\title{
Identification of Group I-III Avian Adenovirus by PCR Coupled with Direct Sequencing of the Hexon Gene
}

\author{
Masaji MASE ${ }^{1,2) *}$, Hiromichi MITAKE ${ }^{3)}$, Toshikazu INOUE $^{1)}$ and Tadao IMADA ${ }^{1)}$ \\ ${ }^{1)}$ National Institute of Animal Health, 3-1-5 Kannondai, Tsukuba, Ibaraki 305-0856 ${ }^{2}$ United Graduate School of Veterinary Sciences, \\ Gifu University, 1-1 Yanagido, Gifu, Gifu 501-1193 and ${ }^{3)}$ Fukui Animal Hygiene Service Center, 69-10-1 Obatake, Fukui, Fukui 918 \\ 8226, Japan
}

(Received 25 March 2009/Accepted 4 May 2009)

ABSTRACT. Polymerase chain reaction (PCR) coupled with direct sequencing of the product of the hexon gene was applied to avian adenoviruses (formerly group I-III). The expected sizes of DNA fragments were successfully amplified by PCR from all of the group I-III avian adenoviruses with our designed primers. The resulting PCR product contained diagnostically relevant hexon sequences that could be used to identify the group and type of avian adenovirus.

KEY WORDS: avian adenovirus, hexon gene, PCR

Birds with avian adenovirus infections may be asymptomatic or show symptoms associated with a variety of clinical and pathologic conditions, including respiratory diseases, marble spleen disease, inclusion body hepatitis, egg drop syndrome, enteritis, and other diseases found in chickens, quails, turkeys, pheasants, geese and guinea fowls $[1,2,10,19]$. The adenoviruses are nonenveloped icosahedral viruses with a diameter of about $70-100 \mathrm{~nm}$. The genome consists of linear double-stranded DNA varying between 26 and $45 \mathrm{~kb}$ depending on the species $[5,6,9,26]$. Major structural proteins are the hexon and the fiber, which is non-covalently linked to the penton base, a structure named as penton [23]. Among them, the hexon protein is the major capsid protein of the non-enveloped icosahedral virion on which type, group and subgroup-specific determinants are located [16].

The adenovirus family has recently been divided into four genera based on phylogenetic relationships [7]: Mastoadenovirus (from mammals), Aviadenovirus (from birds), and 2 recently recognized genera, Atadenovirus and Siadenovirus [4]. Analysis of genome arrangements and DNA sequence data has brought about this recent distinction of the Atadenovirus and Siadenovirus.

Among the adenoviruses, 3 groups of viruses were detected from avian species, and they are called group I, II and III, avian adenovirus (AAV), respectively, which reflected the biological diversity [8]. The first group (group I), Aviadenovirus, the so-called fowl adenovirus is comprised of 12 serotypes from chickens, turkeys, and other species that share a common group antigen [4]. The second group (group II), Siadenovirus, consists of the viruses of hemorrhagic enteritis and marble spleen diseases, and the splenomegaly of chicken. The third division (group III), Atadenovirus, contains the viruses isolated from ducks and

\footnotetext{
* Correspondence to: Mase, M., Research Team for Zoonotic Diseases, National Institute of Animal Health, 3-1-5 Kannondai, Tsukuba, Ibaraki 305-0856, Japan.
}

e-mail:masema@affrc.go.jp from chickens with egg drop syndrome-76 (EDS-76) and which only partially share the group I common antigen.

Routine diagnosis of AAV infections is typically carried out by virus isolation in cell culture, histopathology, or observation of the virus particles using electron microscopy. Characterization of isolated viruses by serotyping is often not carried out because many laboratories do not have access to qualify reference materials. To address this problem, we developed a polymerase chain reaction (PCR) method for amplifying these three groups of AAVs, and we applied this method to some field materials from chickens in Japan.

The following reference group I strains of AAV defined by Kawamura [11] were used in this study: Ote (serotype 1), SR-48 (serotype 2), SR-49 (serotype 3), KR-5 (serotype 4), TR-22 (serotype 5), CR-119 (serotype 6), YR-36 (serotype 7), and TR-59 (serotype 8a). The following reference group II strains of AAV were used in this study: Reed and UA-TF [3]. The following reference group III strains of AAV were used in this study: BC-14 and JPA-1/79 [25]. Group I and III AAVs were grown in primary chicken kidney cell cultures. Group II AAVs were reserved as freeze-dried tissue homogenate (liver). Eleven AAV isolates (except JP/ Hyogo/2007, used as tissue homogenate) collected during routine virological diagnosis activity mainly between 1996 and 2007 were also included in the investigation and are listed in Table $1[14,15,17,21]$.

Viral DNAs from infected culture fluids or tissue homogenates were extracted using QIAamp DNA Micro Kit (Qiagen Inc., Valencia. U.S.A.). The primers were designed from conserved reported sequences identical to a region of the reported hexon protein gene of group I-III AAVs that included the $\mathrm{L} 1$ region, which contained diagnostically relevant sequences that can be used to identify the group and type of avian adenovirus. The following primer set was used in this study: HexF1: 5'-GAYRGYHGGRTNBTGGAYATGGG -3' (from FAdV-1 hexon gene nt positions 283-305, sense) and HeXR1: 5'-TACTTATCNACRG- 
Table 1. AAV isolates employed in this study

\begin{tabular}{lllcc}
\hline Viruses & clinical signs & highest strains and the accession No. & \% homology & Serotype by NT* \\
\hline S-PL1 & Inclusion body hepatitis & Group I, FAdV-2, 685 (AF508947) & 99 & FAdV-2 \\
JP/Kyoto/91 & Egg drop & Group III, 127 (Y09598) & 100 & not tested \\
JP/Fukui-82/96 & Healthy (from feces) & Group I, FAdV-1, 05-50052-2324-2H (EF685377) & 100 & FAdV-1 \\
JP/Fukui-83/96 & Healthy (from feces) & Group I, FAdV-1, 05-50052-2324-2H (EF685377) & 100 & FAdV-1 \\
JP/LVP-1/96 & Hydropericardium syndrome & Group I, FAdV-4, KR-5 (AF508951) & 99 & FAdV-4 \\
JP/Saga/97 & Inclusion body hepatitis & Group I, FAdV-8, 04-53357-113 (EF685497) & 99 & FAdV-8 \\
99ZH & Gizzard Erosion & Group I, FAdV-1, Phelps (U46933) & 99 & FAdV-1 \\
JP/Tokushima/2000GE & Gizzard Erosion & Group I, FAdV-1, Phelps (U46933) & 99 & FAdV-1 \\
JP/Kagawa/2000GE & Gizzard Erosion & Group I, FAdV-1, Phelps (U46933) & 99 & FAdV-1 \\
JP/Oita/2001GE & Gizzard Erosion & Group I, FAdV-1, Phelps (U46933) & 99 & FAdV-1 \\
JP/Hyogo/2007 & Splenomegaly & Group II, Virginia (AY849321) & 97 & not tested \\
\hline
\end{tabular}

* NT: Neutralization test. The serotypes were according to the definition by Kawamura [11].

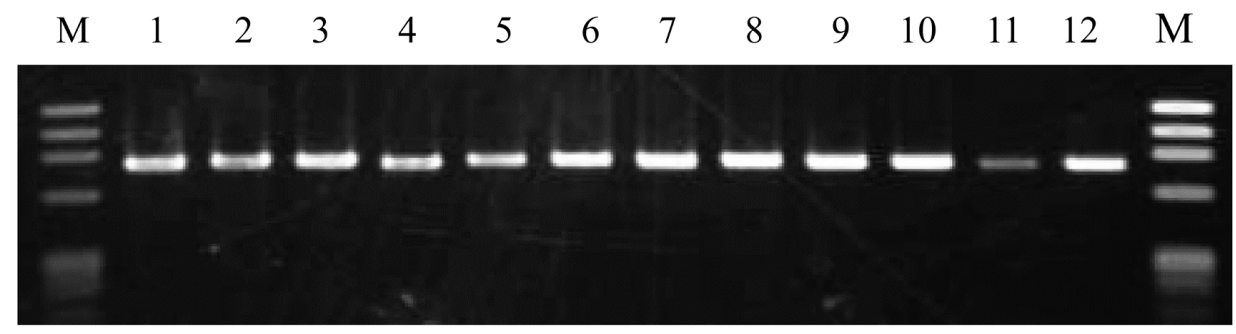

Fig. 1. Lane M, molecular weight marker $\Phi$ X174-HaeIII digest, Lane 1: Ote (Group I serotype 1), Lane 2: SR-48 (Group I serotype 2), Lane 3: SR-49 (Group I serotype 3), Lane 4: KR-5 (Group I serotype 4), Lane 5: TR-22 (Group I serotype 5), Lane 6: CR-119 (Group I serotype 6), Lane 7: YR-36 (Group I serotype 7), Lane 8: TR-59 (Group I serotype 8a), Lane 9: UA-TF (Group II), Lane 10: Reed (Group II), Lane 11: BC-14 (Group III), Lane 12: JPA-1/79 (Group III).

CYTGRTTCCA-3' (from FAdV-1 hexon gene nt positions 1073-1051, antisense). PCR was performed by 35 cycles of $94^{\circ} \mathrm{C}$ for $30 \mathrm{sec}, 55^{\circ}$ for $30 \mathrm{sec}$, and $72^{\circ}$ for $30 \mathrm{sec}$. The predicted size of the PCR products was approximately $800 \mathrm{bp}$.

To identify the group and type of AAV, we directly determined the nucleotide sequences of the generated PCR products. The obtained PCR products of AAVs were purified with Montage (Millipore, Billerica, MA, U.S.A.), according to the manufacturer's instructions. The purified PCR products were used as a template for sequencing on an Applied Biosystems 3100 automated DNA sequencer using dye terminator cycle sequencing chemistry (Big Dye; Applied Biosystems, Foster City, CA, U.S.A.). The purified PCR products were sequenced from both directions. The derived nucleotide sequences were analyzed using GENETYX-Mac ver. 13.0 (Software Development Corp., Tokyo, Japan) and through GenBank searches. The phylogenetic analysis with available sequences from GenBank was conducted using the Clustal X program [22], and the tree was constructed by the neighbor-joining (NJ) method [20].

The serotype of isolated group I AAVs was determined by micro neutralization methods [12]. Briefly, the constant virus and varying serum technique was employed in which two hundred $50 \%$ tissue culture-infected doses $\left(\mathrm{TCID}_{50}\right)$ of virus isolate and twofold dilutions of antiserums, starting from 1:20, were used. The neutralization titers were read 1 week after inoculation and determined to reciprocal titers of the highest serum dilution showing $50 \%$ of the cytopathic effect inhibition. Group III AAV was identified by conventional hemagglutination inhibition assays.

The expected sizes of DNA fragments were successfully amplified by PCR from all the employed AAV samples in this study with our designed primers (Fig. 1). The determination of nucleotide sequences of obtained PCR products revealed the diversity of those lengths (776-797 bp). As shown in Table 1, the results of the identification of field viruses by GenBank searches were almost identical to the results by serological assay in the case of group I and III. In the case of group II AAV (JP/Hyogo/2007), the sequence was identical to that of the Reed strain and most similar to that of a hemorrhagic enteritis virus (HEV) USA strain (Virginia, Accession Number AY849321) with a similarity of $97.3 \%$ by GenBank searches. The grouping and typing were supported by phylogenetic analysis (Fig. 2).

Previously, Xie [24] reported that their method allowed users to amplify all group I-III avian adenoviruses. We applied this method to the AAV employed in this study, but only one type (serotype 1 of group I AAVs) was amplified using their primers, as reported by Meulemans [13]. This failure seemed to be the results of many mismatches in their designed sequence of primers. We also applied another method [18] to the AAV employed, but no amplification product was obtained from FAdV-5 (TR-22 strain). In contrast, the PCR method described in the present study allows 


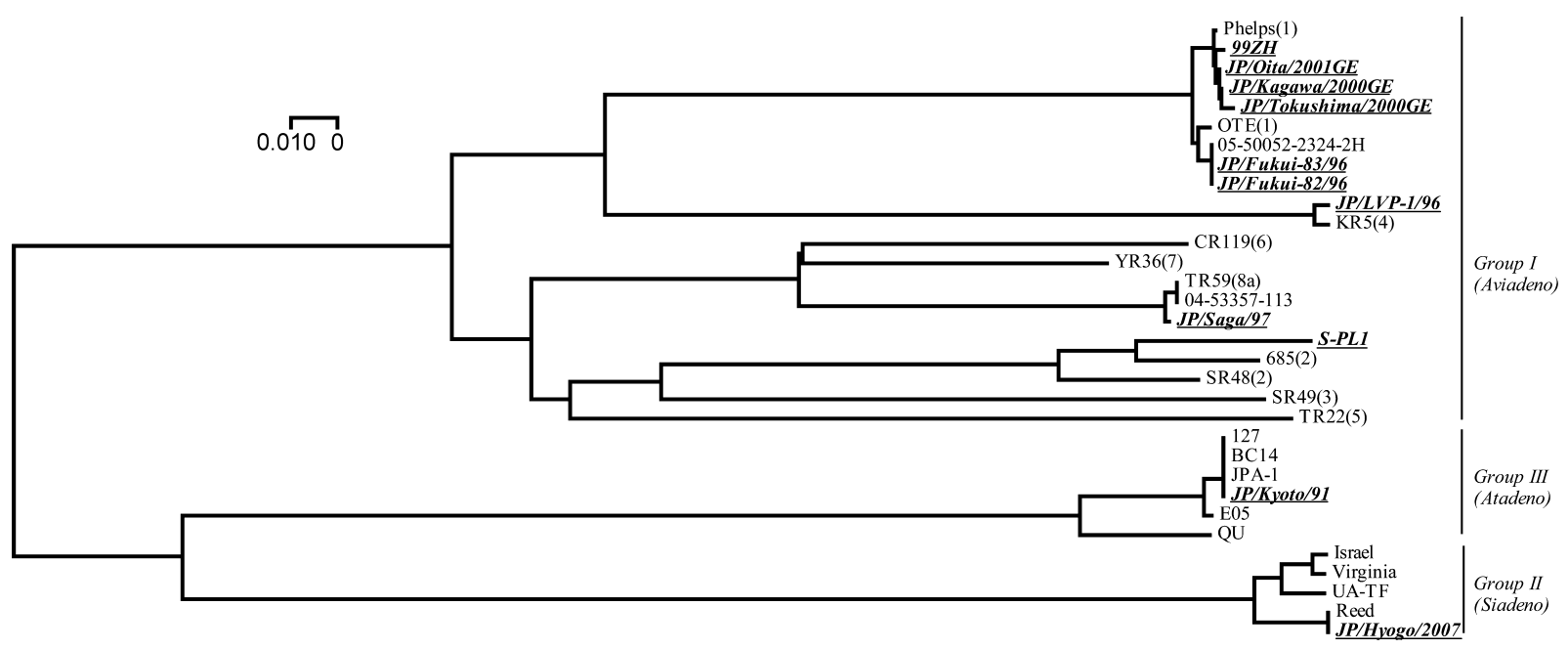

Fig. 2. Phylogenetic tree based on the hexon gene of AAV. Nucleotides 18594-19338 (745 bases) of the complete genome of AAV phelps (GenBank Accession No. U46993) were subjected to phylogenetic analysis. Horizontal distances are proportional to the minimum number of nucleotide differences required to join nodes and sequences. The viruses listed in Table 1 are italicized and underlined.

one to amplify all group I-III avian adenoviruses without extra visible bands.

The genetic diagnosis described here is rapid and technically easy. In some group I AAVs, there exist isolates where serum neutralization cannot clearly differentiate the serotypes [4]. However, genetic differentiation is easy and objective. Therefore, this method would be useful for virological routine diagnosis of all field AAVs. To evaluate our method, we are currently collecting and applying the method to more field materials, with the goal of advancing our understanding of the molecular epidemiology of the AAVs.

ACKNOWLEDGMENT. We would like to thank the veterinary officials of each prefecture for their cooperation in the collection of viral samples.

\section{REFERENCES}

1. Adair, B. M. and Fitzgerald, S. C. 2008. Group I Adenovirus infections. pp. 252-266. In: Diseases of Poultry, 12th ed. (Saif, Y.M., Barners, H.J., Glisson, J.R., Fadly, A.M , McDougald, L.R. and Swayne, D.E. eds.), Ames, Iowa State Press.

2. Baxendale, W. 1978. Egg drop syndrome. Vet. Rec. 102: 450.

3. Beasley, J. N. and Clifton, S. G. 1979. Experimental infection of broiler and Leghorn chickens with virulent and avirulent isolates of hemorrhagic enteritis virus. Avian Dis. 23: 616-621.

4. Benko, M., Harrach, B., Both, G. W., Russell, W. C., Adair, B. M., Adam, E., de Jong, J. C., Hess, M., Johnson, M., Kajon, A., Kidd, A. H., Lehmkuhl, H. D., Li, Q., Mautner, V., PringAkerblom, P. and Wadell, G. 2005. Adenoviridae, pp. 213228. In: Virus Taxonomy. Eighth Report of the Inetrnational Committie on the Taxonomy of Viruses (Fauquet, C.M., Mayo, M.A., Maniloff, J., Desselberger U. and Ball, L.A. eds.), San Diego, CA, U.S.A.

5. Chiocca, S., Kurzbauer, R., Schaffner, G., Baker, A., Mautner, V. and Cotten, M. 1996. The complete DNA sequence and genomic organization of the avian adenovirus CELO. J. Virol. 70: 2939-2949.

6. Clavijo, A., Krell, P. J. and Nagy, E. 1996. Molecular cloning and restriction enzyme mapping of avian adenovirus type 8 DNA. Virus. Res. 45: 93-99.

7. Davison, A. J., Benko, M. and Harrach, B. 2003. Genetic content and evolution of adenoviruses. J. Gen. Virol. 84: 28952908.

8. Fitzgerald, S. D. 2008. Adenovirus infections . pp. 251-252. In: Diseases of Poultry, 12th ed. (Saif, Y.M., Barners, H.J., Glisson, J.R., Fadly, A.M., McDougald, L.R. and Swayne, D.E. eds.). Ames: Iowa State Press.

9. Hess, M., Blocker, H. and Brandt, P. 1997. The complete nucleotide sequence of the egg drop syndrome virus: an intermediate between mastadenoviruses and aviadenoviruses. Virology 238: 145-156.

10. Iltis, J. P., Daniels, S. B. and Wyand, D. S. 1977. Demonstration of an avian adenovirus as the causative agent of marble spleen disease. Am. J. Vet. Res. 38: 95-100.

11. Kawamura, H., Shimizu, F. and Tsubahara, H. 1964. Avian Adenovirus: Its Properties and Serological Classification. Natl. Inst. Anim. Health Q. (Tokyo) 112: 183-193.

12. McFerran, J. B., Clarke, J. K. and Connor, T. J. 1972. Serological classification of avian adenoviruses. Arch. Gesamte. Virusforsch 39: 132-139.

13. Meulemans, G., Couvreur, B., Decaesstecker, M., Boschmans, M. and van den Berg, T. P. 2004. Phylogenetic analysis of fowl adenoviruses. Avian Pathol. 33: 164-170.

14. Nakamura, K., Mase, M., Yamaguchi, S., Shibahara, T. and Yuasa, N. 1999. Pathologic study of specific-pathogen-free chicks and hens inoculated with adenovirus isolated from hydropericardium syndrome. Avian. Dis. 43: 414-423.

15. Nakamura, K., Shoyama, T., Mase, M., Imada, T. and Yamada, M. 2003. Reproduction of hydropericardium syndrome in three-week-old cyclophosphamide-treated specific-pathogenfree chickens by adenoviruses from inclusion body hepatitis. Avian. Dis. 47: 169-174.

16. Norrby, E. 1966. The relationship between the soluble antigens and the virion of adenovirus type 3 . II. Identification and char- 
acterization of an incomplete hemagglutinin. Virology 30: 608-617.

17. Ono, M., Okuda, Y., Yazawa, S., Shibata, I., Tanimura, N., Kimura, K., Haritani, M., Mase, M. and Sato, S. 2001. Epizootic outbreaks of gizzard erosion associated with adenovirus infection in chickens. Avian. Dis. 45: 268-275.

18. Raue, R. and Hess, M. 1998. Hexon based PCRs combined with restriction enzyme analysis for rapid detection and differentiation of fowl adenoviruses and egg drop syndrome virus. $J$. Virol. Methods 73: 211-217.

19. Saifuddin, M. and Wilks, C. R. 1991. Pathogenesis of an acute viral hepatitis: inclusion body hepatitis in the chicken. Arch. Virol. 116: 33-43.

20. Saitou, N. and Nei, M. 1987.The neighbor-joining method: a new method for reconstructing phylogenetic trees. Mol. Biol. Evol. 4: 406-425.

21. Takase, K., Yoshinaga, N., Egashira, T., Uchimura, T. and Yamamoto, M. 1990. Avian adenovirus isolated from pigeons affected with inclusion body hepatitis. J. Vet. Med. Sci. 52:
207-215.

22. Thompson, J. D., Gibson, T. J., Plewniak, F., Jeanmougin, F. and Higgins, D. G. 1997. The CLUSTAL_X windows interface: flexible strategies for multiple sequence alignment aided by quality analysis tools. Nucleic. Acids. Res. 25: 4876-4882.

23. Valentine, R. C. and Pereira, H. G. 1965. Antigens and structure of the adenovirus. J. Mol. Biol. 13: 13-20.

24. Xie, Z., Fadl, A. A., Girshick, T. and Khan, M. I. 1999. Detection of avian adenovirus by polymerase chain reaction. Avian. Dis. 43: 98-105.

25. Yamaguchi, S., Imada, T., Kawamura, H., Taniguchi, S., Saio, H. and Shimamatsu, K. 1981. Outbreaks of egg-drop syndrome-1976 in Japan and its etiological agent. Avian. Dis. 25: 628-641.

26. Zsak, L. and Kisary, J. 1981. Studies on egg drop syndrome (EDS) and chick embryo lethal orphan (CELO) avian adenovirus DNAs by restriction endonucleases. J. Gen. Virol. 56: 8795. 